\title{
O que é natureza da Ciência e qual sua relação com a História e Filosofia da Ciência?
}

\author{
What is the nature of Science and what is its relation with the History \\ and Philosophy of Science?
}

\author{
BRENO ARSIOLI MOURA \\ Universidade Federal do ABC | UFABC
}

\begin{abstract}
RESUMO Este artigo apresenta uma revisão bibliográfica sobre o conceito de natureza da Ciência em trabalhos publicados em livros e periódicos nacionais e internacionais de História e Filosofia da Ciência e de Ensino de Ciências nas últimas três décadas. A partir disso, pretendemos oferecer um aporte para que historiadores, educadores e demais pesquisadores possam ter uma noção abrangente e atual acerca deste conceito, bem como dos caminhos para incorporá-lo ao ensino a partir da História e Filosofia da Ciência.
\end{abstract}

Palavras-chave natureza da Ciência - História e Filosofia da Ciência - ensino.

\begin{abstract}
This paper presents a review of the concept of nature of Science in works published in Brazilian and international books and journals of History and Philosophy of Science and Science Teaching in the last three decades. We intend to offer a basis such that historians, educators and other researchers can have a wide and modern idea about this concept, as well as become aware of the ways to incorporate it to their teaching, starting from the History and Philosophy of Science.
\end{abstract}

Key words nature of Science - History and Philosophy of Science - teaching.

\section{Introdução}

0 propósito de fazer com que alunos e professores aprendam e ensinem não somente Ciência, mas também sobre a Ciência tem se constituído num objetivo pretendido por um grande número de educadores, formadores e acadêmicos. Na literatura especializada do Brasil e do mundo são diversos os artigos, as dissertações e as teses que vêm abordando este assunto, contribuindo para que tenhamos um tema de pesquisa e atuação definido no contexto educacional atual. Segundo estes trabalhos, o entendimento sobre a Ciência envolve compreender o que é denominado de "natureza da Ciência" (NDC).

A natureza da Ciência é entendida como um conjunto de elementos que tratam da construção, estabelecimento e organização do conhecimento científico. Isto pode abranger desde questões internas, tais como método científico e relação entre experimento e teoria, até outras externas, como a influência de elementos sociais, culturais, religiosos e políticos na aceitação ou rejeição de ideias científicas.

A compreensão da natureza da Ciência é considerada um dos preceitos fundamentais para a formação de alunos e professores mais críticos e integrados com o mundo e a realidade em que vivem. Por isso, a defesa pela incorporação 
de discussões sobre a NDC no ensino tem sido uma constante em diversos âmbitos da educação, desde as políticas governamentais até as pesquisas acadêmicas. Neste caminho, tem se destacado a importância da História e Filosofia da Ciência como uma das maneiras de promover uma melhor compreensão da natureza da Ciência, à medida que seus estudos historiográficos trazem elementos que subsidiam discussões acerca da gênese do conhecimento científico e os fatores internos e externos que a influenciam.

Nesta revisão bibliográfica, buscaremos trazer uma síntese do que vem sendo debatido sobre a natureza da Ciência, especialmente no Brasil, partindo de levantamentos realizados em livros e periódicos nacionais e internacionais de História e Filosofia da Ciência e de ensino de Ciências. A intenção é fornecer aos historiadores da Ciência, educadores e demais pesquisadores um panorama geral do que é natureza da Ciência, e como promovê-la se tornou um objetivo bem demarcado na educação científica, principalmente com o aporte da História e da Filosofia da Ciência.

Primeiramente, discutiremos duas concepções de natureza da Ciência presentes na literatura. Em seguida, descreveremos as propostas apresentadas em uma seleção de trabalhos internacionais e nacionais a respeito da NDC publicados nas duas últimas décadas, abordando seus aspectos mais relevantes. Na terceira parte, comentaremos sobre como a História e a Filosofia da Ciência vêm sendo um caminho potencialmente produtivo para incorporar a natureza da Ciência no ensino. Nas considerações finais, retomaremos as questões iniciais para fechar o texto.

A partir desta análise, pretendemos responder às duas perguntas que formam o título deste artigo. Acreditamos que os interessados no tema possam ter em mãos uma visão geral da natureza da Ciência, compreendendo os propósitos por trás dos objetivos para incorporá-lo na educação científica, fomentando futuras ações educacionais na formação básica de estudantes e nos cursos de formação inicial e continuada de professores e, principalmente, contribuindo para aproximá-lo cada vez mais da História e Filosofia da Ciência.

\section{Natureza da Ciência: duas concepções presentes na literatura}

Nas últimas três décadas, o termo "natureza da Ciência" tem sido recorrente em diversas pesquisas acadêmicas e documentos oficiais para a educação. Porém, para grande parte dos não acadêmicos, a expressão ainda pode parecer uma incógnita. 0 que é, afinal, natureza da Ciência?

Responder a esta pergunta não é tarefa trivial. De uma perspectiva bem ampla e geral, podemos dizer que a natureza da Ciência envolve um arcabouço de saberes sobre as bases epistemológicas, filosóficas, históricas e culturais da Ciência. ${ }^{1}$ Compreender a natureza da Ciência significa saber do que ela é feita, como elaborá-la, o que e por que ela influencia e é influenciada.

Uma descrição geral sobre natureza da Ciência, como a mencionada acima, não revela, contudo, características mais detalhadas acerca do que está envolvido no compreender o que é este conceito. Brian J. Alters, ${ }^{2}$ em sua análise a respeito do tema, deixa claro que não é possível pensar em uma única definição da natureza da Ciência. Sob o ponto de vista do autor, muito do que se considerava à época como elemento da natureza da Ciência deveria ser revisto, pois mesmo os filósofos da Ciência - admitidos por ele como os especialistas no assunto - apresentavam muitas discordâncias. Juli T. Eflin, Stuart Glennan e George Reisch ${ }^{3}$ criticam 0 trabalho de Alters, afirmando que os educadores em Ciência deveriam olhar para os filósofos da Ciência não como autoridades, cujas opiniões devem ser seguidas, mas para os debates filosóficos propriamente, vivenciando questões da Filosofia da Ciência. Entre elas, os autores citam: a controvérsia entre realismo e instrumentalismo, racionalismo e historicismo, experimento e teoria.

No contexto atual, podemos olhar para duas visões distintas sobre o que significa natureza da Ciência, que vêm sendo debatidas entre os pesquisadores da área. Por um lado, temos a ideia de que devemos discutir com alunos e professores um conjunto de aspectos ditos "consensuais" a respeito da natureza da Ciência. Estes aspectos seriam uma lista de princípios claros e objetivos do que está envolvido na construção do conhecimento científico. Diversos 
trabalhos têm se fundamentado em listas como essas, inclusive grande parte dos realizados no Brasil. De uma perspectiva diferente, há aqueles que criticam esta ideia, preferindo abordar o conceito de semelhança familiar (family resemblance). Abordaremos as duas visões logo abaixo.

\section{Aspectos consensuais da natureza da Ciência}

No entender de alguns autores, ao trabalhar com natureza da Ciência no ensino, deveríamos abordar seus aspectos consensuais, tidos como características sobre a construção do conhecimento científico que a maioria dos pesquisadores concorda acerca do tema. Entre estes autores, podemos citar William F. McComas e colaboradores, ${ }^{4}$ Stephen Pumfrey ${ }^{5}$ e Daniel Gil-Pérez e colaboradores. ${ }^{6}$ Eles descrevem em seus trabalhos uma lista de aspectos consensuais os quais podemos resumir em cinco tópicos abrangentes, detalhados adiante.

A Ciência é mutável, dinâmica e tem como objetivo buscar explicar os fenômenos naturais. Os três conjuntos de autores citados acima apresentam argumentos que contribuem para corroborar a ideia de que a Ciência não é um conhecimento estático, todavia em constante transformação, sempre com o objetivo de compor modelos explicativos para os fenômenos do mundo natural. Nega-se, portanto, a visão de que a Ciência é um conjunto de verdades absolutas a serem aceitas cegamente. Pelo contrário, por ser conhecimento em contínua mudança, ela está sempre se reformando internamente, revendo seus modelos e bases, o que implica que nossa própria percepção dela também muda com o tempo.

Não existe um método científico universal. Há um consenso muito amplo a respeito deste aspecto da natureza da Ciência. Ao contrário das visões de senso comum sobre o método científico, os pesquisadores na área concordam que não existe um conjunto de regras universais a serem seguidas para fazer Ciência. As metodologias podem ser variadas e os resultados também, abrindo margem para os desacordos. Isso implica dizer que um mesmo fenômeno pode ser estudado e compreendido de modos distintos, todos podendo ser coerentes dentro dos limites de validade dos métodos e concepções empregados para estudá-lo.

A teoria não é consequência da observação/experimento e vice-versa. No senso comum, tem-se a concepção de que uma teoria científica sempre é consequência de um experimento, o qual, se realizado em um determinado número de vezes e de circunstâncias, prova a teoria. Diversos autores na literatura têm combatido essa visão da Ciência. Muito relacionada à concepção do método científico universal, a ideia de uma relação linear entre teoria e experimento corrobora uma noção superficial do processo de construção do conhecimento científico, como se fosse resultado da realização de etapas pré-definidas. Na discussão epistemológica contemporânea há um consenso de que a relação entre teoria e experimento é complexa. Alan F. Chalmers, ${ }^{7}$ em seu icônico 0 que é Ciência, afinal?, dedica três capítulos para desmontar o que ele classifica de indutivismo ingênuo, ou seja, a ideia de que uma observação pode ser imparcial e sempre levar a uma indução limpa e incontestável. 0 autor argumenta que nenhuma observação é livre de uma expectativa ou concepção prévia de quem observa. Neste sentido, podemos dizer que não há uma relação bem definida entre teoria e experimento, no entanto há um consenso de que a Ciência não se constrói sem os dois. Além disso, também há concordância sobre a impossibilidade da prova na Ciência. A Ciência, de outra perspectiva, constrói modelos, explicações, conceitos a respeito do mundo natural que são embasados pelo arcabouço de saberes, metodologias, pressupostos epistemológicos, sociológicos e filosóficos da Ciência. Estas construções são, no fim, sempre provisórias, transformando-se ao longo do tempo e das sucessivas mudanças de contextos científicos, sociais, culturais etc.

A Ciência é influenciada pelo contexto social, cultural, político etc., no qual ela é construída. Este aspecto evidencia a não neutralidade da Ciência e do pensamento científico, isto é, nenhuma ideia científica ou cientista está envolta numa redoma intransponível; pelo contrário, suas concepções, as questões da época, o local em que vivem e as influências que sofrem podem desempenhar um papel importante na aceitação, rejeição e desenvolvimento das ideias da Ciência. 
Embora a influência de fatores externos na Ciência seja um tópico consensual, há um dissenso em relação à natureza e à força destes, como aponta Eflin e colegas. ${ }^{8}$

Os cientistas utilizam imaginação, crenças pessoais, influências externas, entre outros para fazer Ciência. No senso comum, há uma noção de que o cientista está alheio ao mundo ao redor, fazendo uma Ciência neutra e livre de influências. Entretanto, a análise da construção da Ciência revela uma característica de todo cientista: eles são seres humanos comuns, por isso, cometem erros, utilizam de suas crenças e expectativas para elaborar e legitimar suas ideias, têm qualidades e defeitos etc. Isto nos leva a concluir que não há um modelo único de cientista; cada um se faz dentro de seu próprio contexto. 0 cientista de hoje certamente não é o mesmo de ontem, e isso não necessariamente significa que o primeiro seja melhor que o último, apenas que pertencem a contextos diferentes.

\section{O conceito de semelhança familiar (family resemblance)}

Mais recentemente, encontramos na literatura alguns autores que criticam a ideia de aspectos consensuais sobre a natureza da Ciência, preferindo trabalhar com a proposta de semelhança familiar. Entre eles, podemos citar Eflin e colegas e Gürol Irzik e Robert Nola, ${ }^{9}$ cujo trabalho utilizaremos como referência para a discussão à frente.

Irzik e Nola afirmam que a Ciência é tão rica e dinâmica que dificilmente poderíamos descrevê-la sob um conjunto estático de regras ou aspectos. Desta forma, a concepção de natureza da Ciência baseada em aspectos consensuais não parece ser a melhor alternativa. Na concepção deles, nela temos áreas de estudo tão diversificadas que não podemos simplesmente acreditar que os aspectos consensuais da sua natureza descreverão adequadamente todas elas:

\footnotetext{
[...] a visão consensual retrata uma imagem muito monolítica da Ciência e é cega em relação às diferenças entre as disciplinas científicas. Por exemplo, astronomia e cosmologia são muito diferentes, digamos, da química por elas não serem disciplinas experimentais. De forma relacionada, sob a visão consensual, a natureza da Ciência parece ser fixa e atemporal. ${ }^{10}$
}

Irkiz e Nola consideram que estas e outras razões evidenciam as falhas da visão consensual e a necessidade da adoção de outra concepção para a natureza da Ciência. Para eles, a visão mais adequada seria a de semelhança familiar.

Os autores trabalham com quatro categorias de semelhança familiar para a natureza da Ciência: atividades, objetivos e valores, metodologias e regras metodológicas, e produtos. Isto significa, por exemplo, que as áreas da Ciência partilham de semelhanças em seus objetivos ou em seus produtos, como se fossem traços característicos de uma mesma família. Embora não necessariamente sejam idênticas em relação aos pressupostos metodológicos que adotam, as áreas da Ciência possuem semelhanças que as caracterizam como pertencentes a uma mesma família de bases e fundamentos teóricos, procedimentais e metodológicos. De forma geral, o conceito de semelhança familiar diz que as áreas de eletromagnetismo e geoCiências, por exemplo, podem ter objetivos, metodologias e fundamentos diferentes, mas possuem semelhanças entre si que as caracterizam como áreas da Ciência. Detalhamos a proposta de Irzik e Nola a seguir.

Atividades. Para os autores, observar e experimentar são tipicamente atividades da Ciência. Porém, a prática de observar, embora comum em quase todas as áreas da Ciência, pode ser diferente para cada uma delas. Irzik e Nola citam como exemplo o caso das observações na astronomia e na arqueologia. Em ambas, 0 ato de observar constituise parte importante do fazer científico, contudo em cada uma das áreas este se fundamenta em diversas práticas, experiências e habilidades. Enquanto o astrônomo deve ser hábil em posicionar corretamente o telescópio, 0 arqueólogo deve ser capaz de diferenciar fósseis de rochas. Os autores também comentam sobre as diferenças e semelhanças no que diz respeito às práticas materiais - tais como a calibração de um instrumento científico - e às matemáticas. Para eles, independente das diferenças entre as áreas, todas elas pertencem à Ciência por apresentarem semelhanças em relação às atividades que elas desempenham, sejam elas observacionais, materiais ou matemáticas. 
Objetivos e valores. A segunda categoria proposta por Irzik e Nola para trabalhar a natureza da Ciência por meio do conceito de semelhança familiar refere-se aos propósitos e valores da Ciência. Segundo eles, podemos encontrar na literatura uma grande variedade de conceitos abordando as finalidades da Ciência, tais como aqueles defendidos por Kuhn e Popper. Os autores afirmam que dentro de uma concepção de semelhança familiar não precisamos nos ater a algum destes conceitos - 0 que a visão consensual geralmente faz -, apenas entender que cada Ciência individual pode ter um propósito diferente de acordo com as várias interpretações filosóficas que podemos ter delas.

Metodologias e regras metodológicas. Não é possível fazer Ciência sem adotar métodos e regras metodológicas, ou melhor, o conhecimento científico não é construído de forma aleatória, todavia emprega certos parâmetros, alguns comuns a todas as áreas da Ciência. Consoante Irzik e Nola, é evidente que não há uma metodologia única a ser seguida, como destacam os adeptos da visão consensual quando abordam a recusa de um método científico universal. No entanto, a Ciência estaria repleta de regras, algumas alvos de controvérsias, outras aceitas e consideradas importantes, tais como: construir hipóteses/teorias/modelos que são altamente testáveis; evitar fazer revisões ad hoc de teorias; rejeitar teorias inconsistentes; aceitar uma teoria apenas se ela puder explicar todos os sucessos de suas predecessoras; entre outras. ${ }^{11}$ Os autores esclarecem que nem todas as áreas da Ciência utilizam idênticas metodologias e regras metodológicas; há diferenças significativas. Esta característica da Ciência como um todo seria contemplada pela visão de semelhança familiar, visto que mesmo que diversas áreas não compartilhem das mesmas regras, ainda possuiriam aspectos metodológicos semelhantes, o que as uniriam de certa maneira.

Produtos. A Ciência, com suas atividades, busca cumprir seus objetivos a partir de suas metodologias próprias. Isto gera produtos, que podem ser hipóteses, leis, teorias, modelos, dados experimentais etc. Em suas fases finais, os produtos tornam-se conhecimento ou uma crença racional. Assim como para as categorias anteriores, Irzik e Nola salientam que nem todas as áreas da Ciência têm os mesmos produtos. Os autores citam como exemplo o caso da Física - em que certamente há leis - e o da Biologia, ao admitir que a proposição de uma lei é algo que possivelmente sofrerá algum tipo de contestação. Entretanto, como todas as áreas da Ciência possuem algum grau de igualdade em seus produtos, esta é mais uma categoria a ser considerada na concepção de semelhança familiar.

\section{Uma definição sobre a natureza da Ciência (é possível?)}

A definição acerca do que é natureza da Ciência não parece uma tarefa simples. Pela análise das duas concepções acima, podemos perceber similaridades e diferenças notáveis. Por um lado, a ideia de que há aspectos consensuais bem definidos, sobre como a Ciência funciona, parece restrita demais, como apontam Irzik e Nola. Estes, ao defender a concepção de semelhança familiar, a deixam com um caráter muito amplo e aberto. Além disso, destacamos que estas são apenas duas visões, pois um olhar mais apurado para o que os filósofos e os historiadores da Ciência ou os educadores dizem, por exemplo, pode subsidiar inúmeras concepções diferentes, que não necessariamente se assemelhariam com as duas discutidas anteriormente.

De um plano geral, parece-nos claro que discutir a natureza da Ciência é abordar como ela é construída, quer dizer, os elementos, ações, fatores, influências que alicerçam as ideias científicas. Isto passa, a princípio, pela discussão a respeito do método científico. Não há um método científico único, como uma "receita de bolo" a ser seguida passo a passo. Certamente o fazer científico se baseia em métodos, mas não em um único. 0 conhecimento científico é construído com o uso de diversos métodos que envolvem a experimentação, a elaboração e a verificação de hipóteses, as concepções e as expectativas dos cientistas etc.; ou seja, o ponto a ser destacado é a multiplicidade de formas como 0 trabalho científico é feito, e não exatamente como essas formas se relacionam.

Da mesma forma, falar sobre a NDC é relacionar o conhecimento científico com o contexto no qual ele é produzido. A Ciência não está enclausurada em uma bolha, invulnerável aos acontecimentos ao redor. 0 conhecimento científico é obra humana, e como homens pertencentes a uma sociedade - com seus modelos culturais, políticos, históricos, econômicos etc. - , eles trazem à Ciência suas concepções, crenças e anseios. Portanto, falar da natureza 
da Ciência aparentemente deve envolver o esclarecimento de sua indissociabilidade do mundo e da humanidade, de sua mutabilidade - assim como a dos homens -, de seus limites de validade. Exemplos da História e da Filosofia da Ciência não faltam nesse sentido.

À guisa de uma definição acerca do que é natureza da Ciência e em busca de uma resposta à primeira pergunta do título do presente artigo, talvez seja frutífero descrevermos uma, mesmo que reconheçamos suas limitações: estudar a natureza da Ciência significa compreender como o homem constrói o conhecimento científico em cada contexto e em cada época, tendo como base suas concepções filosóficas, ideológicas e metodológicas.

\section{Estudos sobre a natureza da Ciência: análise e resgate histórico}

0 estabelecimento da natureza da Ciência como uma meta a ser alcançada na educação científica teve como grande incentivo os documentos e propostas governamentais para a educação. No contexto internacional, destacam-se as reformas promovidas pela American Association for the Advancement of Science (AAAS) [Associação Americana para o Progresso da Ciência], nos Estados Unidos em 1989 e 1993, e pelo National Curriculum Council (NCC) [Conselho Nacional de Currículo], na Grã-Bretanha em 1989. Nestas reformas, é explícito o propósito de incluir nos currículos do ensino básico discussões sobre a mutabilidade do conhecimento científico - em oposição à visão estática tradicional -, e a relação entre Ciência e os contextos externos a ela e acerca das controvérsias científicas.

No Brasil, destacam-se os Parâmetros Curriculares Nacionais para o Ensino Médio (PCNEM). ${ }^{12}$ Ao tratar das competências a serem desenvolvidas pelos estudantes nas aulas de Física, os PCNEM abordam na categoria "Investigação e Compreensão" uma série de elementos ligados à natureza da Ciência, tais como:

Compreender a construção do conhecimento físico como um processo histórico, em estreita relação com as condições sociais, políticas e econômicas de uma determinada época. [...] Compreender a Física como parte integrante da cultura contemporânea, identificando sua presença em diferentes âmbitos e setores [...]. Reconhecer, em situações concretas, a relação entre Física e ética, seja na definição de procedimentos para a melhoria das condições de vida, seja em questões como do desarmamento nuclear ou em mobilizações pela paz mundial. ${ }^{13}$

Em relação à formação de professores, podemos relacionar aspectos da natureza da Ciência a algumas das metas do Plano Nacional de Educação (PNE), ${ }^{14}$ vigente entre 2001 e 2011. Segundo este documento, os cursos de formação de professores deveriam incorporar, entre outros pontos, uma ampla formação cultural e a análise de temas atuais da sociedade, da cultura e da economia.

De forma complementar, as Diretrizes Curriculares Nacionais para a Formação de Professores da Educação Básica ${ }^{15}$ afirmam que as licenciaturas devem incluir em seus projetos pedagógicos as competências que favoreçam o domínio dos conteúdos a serem socializados, a relação interdisciplinar com outros assuntos e seus significados em diferentes contextos. Afirmam, ainda, que é importante que os futuros professores não apenas discutam questões específicas à sua área de formação, porém que também possuam ampla cultura geral e profissional. Estes pontos indicam que a natureza da Ciência vem sendo contemplada nestas propostas educacionais, ainda que o termo não seja utilizado de forma explícita.

No âmbito da pesquisa acadêmica, são diversos os trabalhos que abordam a temática envolvendo a NDC. Na literatura internacional, cabe destacar a revisão bibliográfica apresentada por Randy Bell e colaboradores, ${ }^{16} \mathrm{em} 2001$, contendo mais de duas centenas de artigos sobre o tópico. Mencionaremos com mais detalhes alguns dos trabalhos referenciados.

Há pouco mais de vinte anos, Norman G. Lederman ${ }^{17}$ apresentou uma análise das pesquisas acerca das concepções de natureza da Ciência de professores e alunos. Segundo o autor, é possível dividir a pesquisa sobre a NDC em 
quatro vertentes distintas: avaliação das concepções de natureza da Ciência dos estudantes; desenvolvimento, uso e avaliação de propostas curriculares com o objetivo de aprimorar as concepções dos estudantes a respeito da natureza da Ciência; avaliação e tentativa de melhorar as visões de professores sobre a NDC; e identificação da relação entre as concepções dos professores, suas práticas docentes e as concepções dos alunos.

Na revisão das pesquisas sobre as concepções dos estudantes acerca da NDC, Lederman concluiu que mesmo utilizando diferentes instrumentos de pesquisa, elas convergiam para um único resultado: os estudantes não apresentavam concepções adequadas sobre a natureza da Ciência ou o pensamento científico. Em relação às propostas curriculares, o autor descreveu um grande conjunto de pesquisas que destacaram, entre outros aspectos, a pouca efetividade da mudança nos currículos a respeito das concepções da NDC dos estudantes. Contudo, de forma geral, elas mostraram que o papel do professor neste processo era fundamental. Isto significava que um professor poderia fazer a diferença, independente do currículo que ele deveria seguir.

Lederman mostrou que as pesquisas sobre as concepções da NDC dos professores apontaram resultados semelhantes às realizadas com os estudantes, isto é, constataram que os professores também tinham visões inadequadas acerca da natureza da Ciência, mas que ainda restavam lacunas em relação a como construir abordagens que promovessem a superação dessas concepções. A respeito das pesquisas que trabalharam com a relação entre as concepções de estudantes e professores, 0 autor afirmou que as atitudes, atividades e decisões em sala de aula pareciam influenciar as ideias dos estudantes sobre a NDC. Isso indicou que, embora um professor possa ter concepções adequadas acerca da natureza da Ciência, se sua prática docente não as traduz em ações em sala de aula, elas não influenciam as visões dos estudantes.

McComas e seus colaboradores ${ }^{18}$ apresentaram um estudo abrangente sobre a inserção da natureza da Ciência na educação científica. Além de discutirem os aspectos consensuais da NDC - como apontamos na seção anterior -, os autores fizeram um breve recorte histórico do desenvolvimento da pesquisa a respeito do tema, relatando em seguida elementos que justificam sua inclusão no âmbito educacional. No entender dos autores, introduzir a natureza da Ciência no ensino é importante, por exemplo, para problematizar as visões inadequadas de estudantes e professores sobre a construção do conhecimento científico e para melhorar o aprendizado de conceitos e o interesse pela Ciência. Por fim, os autores destacaram a importância da NDC na formação de professores, discutindo estudos que indicaram mudanças nas concepções dos professores quando estes cursavam disciplinas específicas acerca do assunto.

No contexto presente, o livro de Douglas Allchin ${ }^{19}$ (2013) destaca-se por apresentar uma ampla revisão das questões envolvendo a incorporação da natureza da Ciência no ensino. 0 autor reúne em sua obra uma série de artigos de sua autoria publicados anteriormente sobre o tema, no entanto revisados e atualizados. Em outra parte, ele disponibiliza estudos de caso envolvendo episódios históricos, a fim de balizar atividades de ensino de natureza da Ciência em situações de sala de aula.

A partir de outra perspectiva, podemos encontrar na literatura trabalhos que analisam propostas de inclusão da natureza da Ciência no ensino. Fouad Abd-El-Khalick e Norman G. Lederman ${ }^{20}$ realizaram uma revisão acerca das propostas de aprimorar as concepções de professores sobre a natureza da Ciência. Os autores fizeram referência à linha de pesquisa citada por Lederman ${ }^{21}$ a respeito das concepções de professores, afirmando que a relação entre elas e as concepções dos alunos seria muito mais complexa que na previsão inicial. Segundo eles, diversas variáveis exerciam um papel determinante na mobilização dos conhecimentos sobre natureza da Ciência pelos professores, entre elas, a pressão para cobrir todo o conteúdo, as questões institucionais envolvidas e o desconforto e inabilidade para se trabalhar com conteúdos deste tipo, afinal, os professores não poderiam ensinar o que não sabiam.

Abd-El-Khalick e Lederman analisaram as propostas de inserção de natureza da Ciência na formação de professores a partir de duas categorias: implícita e explícita. Na abordagem implícita, espera-se que a compreensão da natureza da Ciência seja facilitada por meio da incursão do indivíduo na prática científica, fornecendo elementos subliminares sobre como o conhecimento científico se constrói. A abordagem explícita, por outro lado, muitas vezes se vale da História e Filosofia da Ciência, em que o indivíduo, desde o início da atividade, sabe qual aspecto da NDC será trabalhado. 
Os autores salientaram, entretanto, que a divisão entre os tipos de abordagem está atrelada às ferramentas conceituais que possibilitam que os indivíduos pensem acerca das atividades que eles realizam, ou melhor, não necessariamente uma atividade baseada em História e Filosofia da Ciência será explícita, assim como uma atividade baseada no treinamento científico será implícita.

Ao final do texto, Abd-El-Khalick e Lederman apontaram algumas implicações do estudo para a formação de professores e para a pesquisa. Em relação à primeira, os autores comentaram sobre a necessidade de incluir a natureza da Ciência ao longo de toda a formação, em que os futuros professores sempre tenham a oportunidade de discutir e refletir a respeito de seus vários aspectos. Entre as formas de consolidar essa prática, os autores proporam incentivar os futuros professores a desenvolverem aulas que promovessem a NDC, ou mesmo elaborar métodos de acessar as concepções dos estudantes. Em relação à pesquisa, os autores discutiram as várias perspectivas que podem ser exploradas, tais como o papel da História e Filosofia da Ciência ou a relação entre as concepções de professores e alunos.

No período mais recente, podemos mencionar o trabalho de Maria Teresa Guerra-Ramos, ${ }^{22}$ que apresenta uma análise crítica de diversas pesquisas que abordaram as concepções de professores acerca da natureza da Ciência e suas implicações para 0 ensino. Fouad Abd-El-Khalick, ${ }^{23}$ por sua vez, discute os requisitos para que os professores ensinem com e sobre natureza da Ciência.

Uma das preocupações das pesquisas acadêmicas é analisar as concepções de professores e alunos sobre a natureza da Ciência. Por isso, ao longo das últimas décadas, diversos instrumentos específicos vêm sendo desenvolvidos com 0 intuito de obtê-las. Nesse sentido, destaca-se 0 trabalho de Norman G. Lederman, Philip Wade e Randy L. Bell, ${ }^{24}$ que apresentaram uma revisão histórica a respeito do assunto.

Em outro texto, Norman G. Lederman e colaboradores ${ }^{25}$ descreveram o Views of Nature of Science Questionnaire [Questionário de Visões sobre a Natureza da Ciência], ou simplesmente VNOS, atualmente um dos mais utilizados instrumentos para a verificação de concepções acerca da natureza da Ciência. Os autores afirmaram que havia muitas críticas em relação a estes tipos de instrumento, dentre as quais, sobre seus limites de validade. Por um lado, não estava claro se o respondente interpreta as questões da mesma forma dos proponentes do questionário; por outro, havia 0 problema do questionário refletir as concepções de natureza da Ciência dos proponentes, podendo fazer com que os participantes fossem influenciados a responder o que os proponentes gostariam de obter. Além disso, os instrumentos geralmente tenderiam a classificar as concepções de forma reducionista - "adequadas" ou "inadequadas" -, em vez de elucidar e esclarecer essas visões.

A primeira versão do VNOS foi o VNOS-A, apresentado por Norman G. Lederman e Molly 0’Malley ${ }^{26}$ no início da década de 1990. Em 1998, Fouad Abd-El-Khalick, Randy L. Bell e Norman G. Lederman ${ }^{27}$ descreveram a segunda versão, o VNOS-B, composto por sete questões abertas. A mais atual e que vem sendo amplamente adaptada é o VNOS-C, discutido por Lederman e colaboradores. ${ }^{28} 0$ VNOS-C é composto de dez questões abertas, que buscam traçar as visões dos respondentes sobre diversas perspectivas relacionadas à Ciência. As questões envolvem desde definições acerca da Ciência - "0 que é, na sua visão, Ciência?" -, passando pelo papel dos experimentos - “0 desenvolvimento do conhecimento científico requer experimentos?" -, chegando até a influência de questões sociais e culturais e a importância da imaginação no trabalho dos cientistas.

0 VNOS não é o único instrumento conhecido - vale citar o Views of Science - Technology - Society [Visões de Ciência - Tecnologia - Sociedade], ou VOSTS, desenvolvido por Glen S. Ainkenhead e Alan G. Ryan ${ }^{29}$-, e tampouco foge às críticas. Entre elas, podemos citar o trabalho de Sufen Chen, ${ }^{30}$ que apontou as complicações em responder em um curto período de tempo as questões do VNOS, além de elas serem muito longas e abertas a diversos tipos de interpretação. A autora descreveu outro instrumento, o Views on Science and Education Questionnaire [Questionário sobre Visões de Ciência e Educação], ou VOSE. Este questionário enfatiza sete aspectos da natureza da Ciência que a autora considera relevantes para o ensino básico: 0 caráter provisório do conhecimento científico, a relação entre teoria e observação, a não existência de um método científico universal, as diferenças entre hipótese, teoria e lei, o papel da imaginação, o processo de validação do conhecimento científico e a objetividade e subjetividade na Ciência. 
O VOSE é uma versão adaptada do VOSTS. 0 questionário contém quinze perguntas ou afirmações, seguidas de uma lista de respostas em que os participantes devem ranquear entre "discordo totalmente", "discordo", "incerto/sem comentários", "concordo" e "concordo totalmente". Os sete aspectos da natureza da Ciência enfatizados no questionário estão inseridos implicitamente dentro das respostas, quer dizer, cada pergunta ou afirmação pode abordar diferentes aspectos da NDC, sendo estes refletidos nas respostas disponíveis.

Os trabalhos citados anteriormente formam um pequeno apanhado do que vem sendo discutido nos últimos anos no contexto internacional. No âmbito da pesquisa acadêmica nacional, também podemos citar um bom conjunto de trabalhos que abordam o tema.

João Batista Siqueira Harres, ${ }^{31}$ por exemplo, apresentou uma revisão das pesquisas sobre as concepções de professores acerca da natureza da Ciência. Daniel Iria Machado e Roberto Nardi ${ }^{32}$ discutiram como softwares educacionais podem contribuir para o ensino de Física moderna e de natureza da Ciência. Marcio Medina e Marco Braga ${ }^{33}$ descreveram e analisaram uma proposta de trabalho com natureza da Ciência por meio da peça teatral "A vida de Galileu", de Bertold Brecht. Argus Vasconcelos de Almeida e Carmen Roselaine de Oliveira Farias ${ }^{34}$ realizaram uma revisão teórica ao respeito do assunto a partir do contexto da formação inicial de professores de Ciências biológicas, abordando o papel que as práticas curriculares podem exercer no intuito de trabalhar a natureza da Ciência nas licenciaturas.

Os textos acadêmicos mencionados trabalham sob a perspectiva geral da natureza da Ciência. Há, pois, uma grande quantidade de artigos nas literaturas internacional e nacional que discutem a NDC e como incorporá-la no ensino a partir do viés da História e Filosofia da Ciência. Estes trabalhos serão discutidos adiante.

\section{Natureza, História e Filosofia da Ciência: aproximações}

A contribuição da História e da Filosofia da Ciência para melhorar o ensino tem figurado como um ponto de

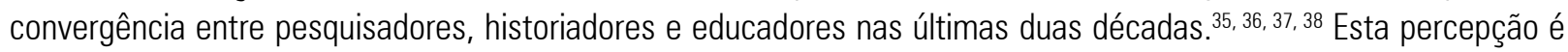
corroborada pelo significativo aumento do número de trabalhos publicados sobre o tema nos periódicos especializados, conforme relatado por Elder Sales Teixeira, Ileana Maria Greca e Olival Freire Jr. ${ }^{39}$ e Thais Cyrino de Mello Forato e colaboradores ${ }^{40}$ e em livros organizados por historiadores da Ciência e educadores. ${ }^{40,41}$

Na análise realizada por Teixeira e colaboradores, ${ }^{42}$ é possível notar uma boa quantidade de textos que abordam o potencial da História e Filosofia da Ciência como caminhos para discutir aspectos da NDC. Esta tendência tem se destacado nos últimos anos, originando uma gama de trabalhos específicos que vem contribuindo para consolidar uma área de pesquisa bem demarcada no contexto atual.

No âmbito das publicações internacionais, destaca-se 0 trabalho de Michael Matthews, ${ }^{43}$ publicado originalmente em 1992 e traduzido para o português em 1995. No texto, ele fez um amplo detalhamento histórico sobre como a inserção da História e Filosofia da Ciência vêm se reaproximando das questões de ensino, tornando-se uma meta inequívoca da educação científica atual. 0 autor ressaltou ao longo do texto de que forma o estudo de conteúdos históricos e filosóficos têm contribuído para aprimorar as concepções de estudantes e professores acerca da natureza do conhecimento científico. Em outro trabalho, Matthews ${ }^{44}$ discutiu alguns deles:

A História promove uma melhor compreensão dos conceitos e métodos científicos;

Abordagens históricas relacionam o desenvolvimento do pensamento individual com o desenvolvimento das ideias científicas;

A História da Ciência é intrinsicamente valiosa. Episódios importantes na História da Ciência e da cultura - a Revolução Científica, darwinismo, a descoberta da penicilina, entre outras coisas - deveriam ser familiares a todos os estudantes; 
A História é necessária para compreender a natureza da Ciência;

A História contrapõe o cientificismo e o dogmatismo que são comumente encontrados em textos científicos e aulas de Ciências;

A História, pela análise da vida e da época dos cientistas, humaniza os assuntos da Ciência, fazendo-os menos abstratos e mais interessantes para os estudantes;

A História permite que sejam feitas relações entre tópicos e disciplinas da Ciência, assim como com outras disciplinas acadêmicas;

A História fornece a natureza integradora e independente das conquistas humanas.

Dessa forma, a História e Filosofia da Ciência formam um caminho possível para a discussão de natureza da Ciência, porque evidenciam os meandros da construção do conhecimento científico, contextualizando a Ciência. Estudar a História e Filosofia da Ciência é compreender as origens das ideias científicas e as diversas influências sofridas e exercidas por ela. No contexto nacional, Luiz 0. 0. Peduzzi, ${ }^{46}$ Roberto de Andrade Martins ${ }^{47,48}$ e João Zanetic ${ }^{49}$ também apontaram inúmeros benefícios da utilização da História e Filosofia da Ciência, estabelecendo relações entre o estudo destes conteúdos e a compreensão da natureza da Ciência e do fazer científico.

$\mathrm{Na}$ Literatura, podemos encontrar diversos trabalhos que abordam como a História e Filosofia da Ciência podem ser trabalhadas para discutir aspectos da NDC. David W. Rudge e Eric M. Howe, ${ }^{50}$ por exemplo, discutiram o que eles denominaram de abordagem explícita e reflexiva da História da Ciência. Para os autores, os estudantes compreendiam mais sobre a Ciência e o processo de construção do conhecimento científico quando eram colocados a pensar como os cientistas do passado fizeram. Uma abordagem explícita significa que os estudantes são apresentados desde o início das atividades aos aspectos da natureza da Ciência que serão trabalhados. De forma complementar, uma abordagem reflexiva significa que eles devem pensar a respeito destes aspectos a fim de desenvolver uma compreensão mais ampla do que é Ciência. Por meio desta discussão, os autores pretenderam fazer uma crítica ao texto de Martin Monk e Jonathan Osbourne, ${ }^{51}$ que advogaram por uma abordagem implícita da História da Ciência. Basicamente, a crítica de Rudge e Howe se fundamentou no argumento de que simplesmente fazer com que os estudantes comparem suas ideias com aquelas dos cientistas do passado - como propôs Monk e Osbourne - não seria produtivo. A melhor alternativa seria fazer com que eles pensassem, refletissem, se engajassem como os cientistas do passado por meio de uma abordagem explícita e reflexiva. Ao final do texto, Rudge e Howe apresentaram um exemplo dessa abordagem, aplicado entre professores em serviço, utilizando como tópico a anemia falciforme. Recentemente, David W. Rudge e colegas ${ }^{52}$ publicaram outro texto contendo mais um exemplo de abordagem explícita e reflexiva, dessa vez sobre 0 fenômeno do melanismo industrial.

Allan R. Irwin ${ }^{53}$ discutiu os resultados da aplicação de um curso fundamentado na discussão histórica acerca do conceito de átomo oferecido para alunos da educação básica, sendo ele também o professor do curso. Foram estudadas duas turmas, uma que passou pela discussão histórica e outra cujo curso foi oferecido nos moldes tradicionais. Segundo Irwin, seu propósito foi mostrar aos estudantes exemplos de como os cientistas podem especular mesmo com poucas evidências, o que eventualmente pode levar a significativas mudanças no conhecimento científico. 0 autor encontrou, porém, um resultado não muito satisfatório em relação ao aprendizado do conceito contemporâneo de átomo, ou seja, os alunos que passaram por uma discussão histórica não "aprenderam melhor" que os do grupo tradicional. Contudo, Irwin afirmou que em relação à natureza da Ciência, o curso fundamentado nas discussões históricas mostrou um caminho interessante.

De maneira similar, todavia mais abrangente, Fouad Abd-El-Khalick e Norman G. Lederman ${ }^{54}$ apresentaram uma análise da influência de cursos de História da Ciência sobre as visões de universitários e professores em formação. Os autores salientaram que, no contexto da época em que escreviam, não havia evidências empíricas suficientes que atestavam a contribuição da História da Ciência para o entendimento da NDC, embora essa concepção estivesse comumente presente nas falas dos pesquisadores. Os resultados obtidos indicaram que a realização de um curso de História da 
Ciência não levou automaticamente a uma melhor compreensão da natureza da Ciência. Havia uma série de obstáculos assinalados pelos autores: 0 fato de os estudantes serem apresentados a narrativas históricas prontas; as dificuldades em relação ao entendimento e interpretação dos materiais históricos, cujas ideias que os compõem podem ser vistas como erradas; os objetivos dos cursos de História da Ciência, podendo o ensino da natureza da Ciência ser ofuscado por outros propósitos, entre outros. Os autores afirmaram que a abordagem explícita de aspectos da natureza da Ciência na discussão de episódios históricos era uma estratégia mais frutífera que uma abordagem implícita, embora reconhecessem que os dados apresentados no texto não ofereciam um bom suporte empírico para corroborar essa posição.

William F. McComas ${ }^{55}$ listou os exemplos de episódios da História da Ciência que poderiam ser utilizados para trabalhar aspectos da natureza da Ciência presentes em um conjunto de livros. 0 autor destacou que apenas livros sobre a NDC destinados ao público em geral foram utilizados, isto é, aqueles direcionados a um público exclusivamente acadêmico foram excluídos da pesquisa. Um dos livros usados foi o de Chalmers (0 que é Ciência, afinal?). McComas descreveu cerca de 80 exemplos dos livros e os alinhou com aspectos consensuais da natureza da Ciência, tais como o papel da criatividade no desenvolvimento das ideias científicas e a importância da evidência empírica.

Entre os pesquisadores nacionais, há uma significativa quantidade de trabalhos que discutem a História e Filosofia da Ciência como recurso para trabalhar questões de natureza da Ciência. Cibelle Celestino Silva e Maria Elice Brzezinski Prestes $^{56}$ reuniram em seu livro um conjunto de trabalhos apresentados no primeiro congresso latino-americano do International History, Philosophy and Science Teaching Group [Grupo Internacional de História, Filosofia e Ensino de Ciências], realizado em 2010. A terceira parte do livro é dedicada exclusivamente a textos sobre natureza da Ciência, constituindo uma importante e atual referência nacional acerca do tema.

Thais Cyrino de Mello Forato, ${ }^{57}$ por sua vez, descreveu os resultados da aplicação de um curso piloto a respeito da natureza da luz entre estudantes de ensino médio. 0 curso tinha como propósito trabalhar com os alunos cinco aspectos da NDC por meio do estudo histórico da óptica dos séculos XVII a XIX. A autora elaborou um extenso conjunto de atividades e materiais: uma linha do tempo, textos de apoio para alunos e professor, uma peça de teatro, slides para as aulas, entre outros. Por fim, a autora apresentou uma lista de parâmetros que devem ser considerados na pesquisa em História e Filosofia da Ciência no ensino, compreendendo a definição dos objetivos pedagógicos, do nível de profundidade das discussões em sala de aula, os materiais a serem adotados, a preparação do professor etc. Em outros textos, a autora e colaboradores apresentam alguns resultados mais específicos da pesquisa. ${ }^{58,59}$

Charbel Niño El-Hani, Eraldo José Madureira Tavares e Pedro Luís Bernardo da Rocha ${ }^{60}$ discutiram os resultados da aplicação de uma proposta de ensino de História e Filosofia da Ciência com alunos de licenciatura em Ciências Biológicas. A proposta foi fundamentada na discussão da problemática da evolução, valendo-se da leitura e estudo pelos alunos de fontes secundárias e primárias, incluindo textos de figuras conhecidas, tais como Lamarck e Darwin. Para a coleta de dados, um dos instrumentos utilizados foi uma versão traduzida do VNOS-C. A partir dela, os autores elaboraram um conjunto de categorias para classificar as respostas dos alunos para cada pergunta do questionário.

Marco Antonio Moreira, Neusa T. Massoni e Fernanda Ostermann ${ }^{61}$ relataram a implementação de uma disciplina de História e Epistemologia da Ciência em um curso de formação de professores de Física e sua contribuição para transformar as concepções dos licenciandos sobre a natureza da Ciência. A disciplina contemplava desde a discussão de episódios da História da Física considerados importantes - tais como as ideias aristotélicas e a revolução científica do século XVII - até questões de epistemologia da Ciência, fazendo referência a teóricos como Kuhn e Popper. A partir da coleta de dados por meio de questionários, os autores concluíram que a disciplina contribuiu para aprimorar as visões dos participantes sobre a NDC. Análises semelhantes, no entanto em outros contextos, foram realizadas por Giuliano J. S. Alves Pereira e André Ferrer P. Martins ${ }^{62}$ e Maria da Conceição Marinho Oki e Edílson Fortuna Moradillo. ${ }^{63}$

Luiz 0. 0. Peduzzi, Danielle Nicolodelli Tenfen e Marinês Domingues Cordeiro ${ }^{64}$ analisaram as possibilidades de discussão de tópicos de natureza da Ciência a partir de cinco animações em flash desenvolvidas para a disciplina Evolução dos Conceitos da Física, oferecida à distância na Universidade Federal de Santa Catarina (UFSC). As animações tratam de períodos históricos relevantes para a Ciência, como o desenvolvimento da compreensão acerca do 
funcionamento do universo, desde as ideias cosmológicas de Descartes até o estabelecimento da teoria newtoniana da gravitação universal ou questões envolvendo a teoria da relatividade de Einstein. Ao longo das cenas, as animações abordam aspectos da natureza da Ciência, por exemplo, o papel da imaginação dos cientistas no desenvolvimento de suas ideias, a mutabilidade do conhecimento científico e a influência de fatores externos. Os autores destacaram o potencial educacional das animações para discussões a respeito da NDC, especialmente antes do trabalho com os conteúdos da disciplina de Evolução dos Conceitos da Física.

Breno Arsioli Moura ${ }^{65}$ analisou como a História da Ciência, ao trabalhar elementos de natureza da Ciência, poderia promover uma formação crítico-transformadora de professores. 0 autor apresentou uma proposta de ensino contextualizado de episódios históricos para professores em formação, envolvendo, entre outros contextos, a discussão de aspectos metacientíficos relacionados aos episódios. Os resultados de uma aplicação-piloto em uma universidade federal brasileira apontaram o desenvolvimento de uma percepção crítica sobre Ciência e educação mais abrangente por parte dos licenciandos participantes.

Na interface entre História e Filosofia da Ciência e natureza da Ciência, cabe destacar os trabalhos do grupo Teknê. ${ }^{66}$ Com uma extensa lista de cursos, eventos, livros e artigos publicados, o grupo vem contribuindo para consolidar a perspectiva de que os episódios históricos podem facilitar a compreensão de aspectos da construção do conhecimento científico. Grande parte das propostas do grupo é discutida nos textos publicados por seus membros em revistas da área de ensino de Ciências. ${ }^{67,68,69}$

Cibelle Celestino Silva e Breno Arsioli Moura ${ }^{70,71}$ apontaram como 0 episódio envolvendo a aceitação da óptica newtoniana evidenciava um conjunto de aspectos da natureza da Ciência, entre eles, a influência de fatores sociais e culturais e as mudanças que as teorias científicas originais podem sofrer ao longo dos anos, destacando o caráter mutável do conhecimento científico. Uma proposta semelhante foi apresentada por Marinês Domingues Cordeiro e Luis 0. 0. Peduzzi, ${ }^{72}$ em relação ao episódio sobre o desenvolvimento dos estudos acerca da radioatividade.

Os trabalhos mencionados acima representam apenas uma parcela da grande variedade de textos que falam da relação entre História e Filosofia da Ciência e natureza da Ciência disponíveis na literatura. Um olhar para os trabalhos publicados em eventos da área, tais como o Seminário Nacional de História da Ciência e Tecnologia (SNHCT) ou os encontros da Associação de Filosofia e História da Ciência do Cone Sul (AFHIC), bem como para aqueles da área de ensino, tais como o Encontro de Pesquisa em Ensino de Física (EPEF), Encontro Nacional de Ensino de Química (ENEQ), o Simpósio Nacional de Ensino de Física (SNEF) e o Encontro Nacional de Pesquisa em Educação em Ciências (ENPEC) - citando apenas os nacionais - ou mesmo as dissertações e teses produzidas nos programas de pós-graduação, certamente contribuiria para aumentar este número. Entretanto, podemos afirmar, com segurança, que a área de pesquisa na interface em História e Filosofia da Ciência e natureza da Ciência está cada vez mais na pauta de pesquisa de historiadores e educadores. Esta constatação ressalta que entender o que é natureza da Ciência e incorporá-la no ensino tem se constituído como um propósito a ser alcançado atualmente.

Dessa forma, a fim de respondermos à segunda questão do título deste ensaio, podemos dizer que há uma estreita relação entre natureza da Ciência e História e Filosofia da Ciência, principalmente quando se fala na discussão de propostas de se contextualizar a educação científica. Os conteúdos históricos e filosóficos têm sido utilizados como um potencial recurso pedagógico para trabalhar aspectos do desenvolvimento da Ciência, o que é corroborado pela significativa quantidade de trabalhos nesta interface.

\section{Considerações finais}

A revisão apresentada buscou esclarecer ao leitor o que é natureza da Ciência e, de uma forma geral, como sua introdução no ensino tornou-se um assunto de pesquisa e indagação bem definido nos últimos anos. Da mesma 
maneira, abordou como a NDC vem sendo discutida por meio da História e Filosofia da Ciência. No caso das pesquisas brasileiras, é possível notar a presença de um bom número de trabalhos nessa linha, indicando que o país é um nicho a ser extensamente explorado pelos pesquisadores.

Pela análise acima, podemos entender que a natureza da Ciência refere-se aos elementos envolvidos na construção do conhecimento científico, desde questões internas relacionadas ao método científico e à relação entre teoria e observação, até questões externas, como o papel da criatividade ou de concepções prévias dos cientistas no desenvolvimento de suas ideias. Podemos trabalhar sobre essa concepção a partir de, pelo menos, duas vertentes distintas, a dos aspectos consensuais e a da semelhança familiar. Escolher uma parece depender mais de orientações ideológicas, filosóficas e epistemológicas do que simplesmente apelar para um reducionismo de "uma está certa, outra está errada".

Se hoje não se discute mais se a natureza da Ciência é importante, talvez o desafio a ser enfrentado neste momento seja o como incorporar, principalmente utilizando a História e a Filosofia da Ciência como caminho. Nos textos acima elencados, podemos observar os diversos obstáculos enfrentados pelos pesquisadores ao longo de suas tentativas de discutir a natureza da Ciência entre professores e alunos. Por isso, o momento parece propício para a construção e avaliação de ações concretas e não pontuais. É preciso, assim, um esforço de tornar a incorporação da natureza da Ciência como um projeto amplo e articulado tanto na formação de professores - que precisam ter uma visão mais adequada de Ciência - quanto de alunos, cujas concepções distorcidas e simplistas precisam ser trabalhadas, problematizadas e superadas.

0 presente artigo pretendeu, nesse sentido, oferecer um panorama do que foi e vem sendo feito. Com isso, pesquisadores brasileiros iniciantes ou experientes no tema podem ter uma visão geral do que vem sendo discutido até 0 momento, reforçando suas buscas por referenciais na área e possibilitando a expansão da interlocução entre os trabalhos produzidos no país e no exterior. A partir disso, acreditamos ser possível estabelecer novos rumos, consolidar e ampliar aqueles que vêm apresentando bons resultados. Não se pode antever o que será da relação entre natureza, História, Filosofia e Ensino das Ciências nos próximos anos, mas por este retrospecto, o cenário futuro parece ser muito promissor.

\section{Notas e referências bibliográficas}

Breno Arsioli Moura é doutor e mestre em Ensino de Física, com ênfase em História da Ciência. Atua com pesquisa em História da Física e na interface entre História da Ciência e Ensino. Atualmente, é professor da Universidade Federal do ABC (UFABC) e docente permanente da Pós-Graduação em Ensino, História e Filosofia das Ciências e Matemática da mesma instituição. E-mail: breno.moura@ufabc.edu.br.

1 LEDERMAN, N. G. Nature of Science: Past, present, and future. In: ABELL, S.; LEDERMAN, N. G. Handbook of research in Science Education. New York: Routledge, 2007.

2 ALTERS, B. J. Whose nature of Science? Journal of Research in Science Teaching, v. 34, n. 1, p. 39-55, 1997.

3 EFLIN, J. T.; GLENNAN, S.; REISCH, G. The nature of Science: A perspective from the Philosophy of Science. Journal of Research in Science Teaching, v. 36 , n. 1, p. 107-116, 1999.

4 McCOMAS, W. F.; ALMAZROA, H.; CLOUGH, M. P. The nature of Science in Science education: An introduction. Science \& Education, v. 7, n. 6, p. 511-532, 1998.

5 PUMFREY, S. History of Science in the National Science Curriculum: A critical review of resources and their aims. British Journal for the History of Science, v. 24, n. 1, p. 61-78, 1991.

6 GIL-PERÉZ, D.; MONTORO, I. F.; ALÍS, J. C.; CACHAPUZ, A.; PRAIA, J. Para uma imagem não deformada do trabalho científico. Ciência \& Educação, v. 7, n. 2, p. 125-153, 2001.

7 CHALMERS, A. F. 0 que é Ciência, afinal? São Paulo: Editora Brasiliense, 2007.

8 EFLIN, J. T.; GLENNAN, S.; REISCH, G., op. cit., p. 109.

9 IRZIK, G.; NOLA, R. A family resemblance approach to the nature of Science for Science education. Science \& Education, v. 20, p. 591-607, 2011.

10 Idem, op. cit., p. 593. 
12 BRASIL. Ministério da Educação, Secretaria de Educação Média e Tecnológica. Parâmetros curriculares nacionais: ensino médio. Brasília: Ministério da Educação, 1999.

13 BRASIL. Secretaria da Educação Média e Tecnológica. PCN + ensino médio: orientações educacionais complementares aos parâmetros curriculares nacionais. Ciências da Natureza, Matemática e suas tecnologias. Brasília: MEC/SEMTEC, 2002. p. 67-8.

14 BRASIL. Ministério da Educação. Plano Nacional de Educação - PNE. Brasília: Inep, 2001a.

15 BRASIL. Resolução CNE/CP 1, de 18 de fevereiro de 2002. Institui diretrizes curriculares nacionais para a formação de professores da educação básica, em nível superior, curso de Licenciatura, de Graduação plena. Brasília: DOU, 2002.

16 BELL, R.; ABD-EL-KHALICK, F; LEDERMAN, N. G.; McCOMAS, W. F. The nature of Science and Science education: A bibliography. Science \& Education, v. 10, n. 1-2, p. 187-204, 2001.

17 LEDERMAN, N. G. Student's and teacher's conceptions of the nature of Science: A review of the research. Journal of Research in Science Teaching, v. 29, n. 4, p. 331-359, 1992.

18 McCOMAS, W. F.; ALMAZROA, H.; CLOUGH, M. P., op. cit.

19 ALLCHIN, D. Teaching the nature of Science - Perspectives and resources. Saint Paul: SHiPS Education Press, 2013.

20 ABD-EL-KHALICK, F.; LEDERMAN, N. G. Improving Science teachers' conceptions of the nature of Science: A critical review of the literature. International Journal of Science Education, v. 22, n. 7, p. 665-701, 2000.

21 LEDERMAN, N. G., op. cit.

22 GUERRA-RAMOS, M. T. Teachers' ideas about the nature of Science: A critical analysis of research approaches and their contribution. Science \& Education, v. 21, n. 5, p. 631-655, 2012.

23 ABD-EL-KHALICK, F. Teaching with and about nature of Science, and Science teacher knowledge domains. Science \& Education, on-line version (2012).

24 LEDERMAN, N. G.; WADE, P. D.; BELL, R. L. Assessing understanding of the nature of Science: A historical perspective. In: McCOMAS, W. F. (Org.) The nature of Science in Science education: Rationales and strategies. The Netherlands: Kluwer Academic, 1998.

25 LEDERMAN, N. G.; ABD-EL-KHALICK, F.; BELL, R. L.; SCHWARTZ, R. S. Views of nature of Science questionnaire: Toward valid and meaningful assessment of learners' conceptions. Journal of Research in Science Teaching, v. 39, n. 6, p. 497-521, 2002.

26 LEDERMAN, N. G.; O'MALLEY, M. Students' perceptions of tentativeness in Science: Development, use, and sources of change. Science Education, v. 74 , p. 225-239, 1990.

27 ABD-EL-KHALICK, F.; BELL, R. L.; LEDERMAN, N. G. The nature of Science and instructional practice: Making the unnatural natural. Science \& Education, v. 82, p. 417-436, 1998.

28 LEDERMAN, N. G.; WADE, P. D.; BELL, R. L., op. cit.

29 AIKENHEAD, G. S.; RYAN, A. The development of a new instrument: "Views on Science-Technology-Society" (VOSTS). Science \& Education, v. 76, p. 477491, 1992.

30 CHEN, S. Development of an instrument to assess views on nature of Science and attitudes toward teaching Science. Science \& Education, v. 90, p. 803819, 2006.

31 HARRES, J. B. S. Uma revisão de pesquisas nas concepções de professores sobre a natureza da Ciência e suas implicações para o ensino. Investigações em Ensino de Ciências, v. 4, n. 3, p. 197-211, 1999.

32 MACHADO, D. I.; NARDI, R. Construção de conceitos de Física moderna e sobre natureza da Ciência com o suporte da hipermídia. Revista Brasileira de Ensino de Física, v. 28, n. 4, p. 473-485, 2006.

33 MEDINA, M.; BRAGA, M. 0 teatro como ferramenta de aprendizagem da Física e de problematização da natureza da Ciência. Caderno Brasileiro de Ensino de Física, v. 27, n. 2, p. 313-333, 2010.

34 ALMEIDA, A. V.; FARIAS, C. R. O. A natureza da Ciência na formação de professores: reflexões a partir de um curso de licenciatura em Ciências Biológicas. Investigações em Ensino de Ciências, v. 16, n. 3, p. 473-488, 2011.

35 MARTINS, R. A. Introdução: a História das Ciências e seus usos na educação. In: SILVA, C. C. (Org.). Estudos de História e Filosofia das Ciências: subsídios para aplicação no ensino. São Paulo: Livraria da Física, 2006.

36 PEDUZZI, L. O. O. Sobre a utilização didática da História da Ciência. In: PIETROCOLA, M. (Org.). Ensino de Física: conteúdo, metodologia e epistemologia numa concepção integradora. Florianópolis: Editora da UFSC, 2001.

37 MATTHEWS, M. R. Science teaching - The role of History and Philosophy of Science. New York: Routledge, 1994.

38 BASSALO, J. M. F. A importância do estudo da História da Ciência. Revista da SBHC, n. 8, p. 57-66, 1992.

39 TEIXEIRA, E. S.; GRECA, I. M.; FREIRE JR., 0. Uma revisão sistemática das pesquisas publicadas no Brasil sobre o uso didático de História e Filosofia da Ciência no ensino de Física. In: PEDUZZI, L. 0. 0.; MARTINS, A. F. P.; FERREIRA, J. M. H. Temas de História e Filosofia da Ciência no ensino. Natal: EDUFRN, 2012.

40 FORATO, T. C. M.; MOURA, B. A.; PRESTES, M. E. B. Bibliografia sobre a utilização da História e Filosofia da Ciência no ensino de Ciências e Biologia. Boletim de História e Filosofia da Biologia, v. 2, n. 3, p. 4-11, 2008.

41 SILVA, C. C. (Org.) Estudos de História e Filosofia das Ciências: subsídios para aplicação no ensino. São Paulo: Livraria da Física, 2006.

42 PEDUZZI, L. O. O.; MARTINS, A. F. P.; FERREIRA, J. M. H. Temas de História e Filosofia da Ciência no ensino. Natal: EDUFRN, 2012.

43 TEIXEIRA, E. S.; GRECA, I. M.; FREIRE JR., 0., op. cit.

44 MATTHEWS, M. R. História, Filosofia e ensino de Ciências: a tendência atual de reaproximação. Caderno Catarinense de Ensino de Física, v. 12, n. 3, p. 164-214, 1995. 
46 PEDUZZI, L. O. 0., op. cit.

47 MARTINS, R. A., op. cit.

48 MARTINS, R. A. Sobre o papel da História da Ciência no ensino. Boletim da Sociedade Brasileira de História da Ciência, n. 9, p. 3-5, 1990.

49 ZANETIC, J. Física também é cultura. Tese (Doutorado em Educação) $\square$ Faculdade de Educação, Universidade de São Paulo, São Paulo, 1989.

50 RUDGE, D. W.; HOWE, E. M. An explicit and reflective approach to the use of History to promote understanding of the nature of Science. Science $\&$ Education, v. 18, n. 5, p. 561-580, 2009.

51 MONK, M.; OSBOURNE, J. Placing the History and Philosophy of Science on the curriculum: A model for the development of a pedagogy. Science \& Education, v. 81, p. 405-424, 1997.

52 RUDGE, D. W.; CASSIDY, D. P.; FULFORD, J. M.; HOWE, E. M. Changes observed in views of nature of Science during a historically based unit. Science \& Education, on-line version (2013).

53 IRWIN, A. R. Historical case studies: Teaching the nature of Science in context. Science Education, v. 84, n. 1, p. 5-26, 2000.

54 ABD-EL-KHALICK, F.; LEDERMAN, N. The influence of History of Science courses on student's views of nature of Science. Journal of Research in Science Teaching, v. 37, n. 10, p. 1.057-1.095, 2000.

55 McCOMAS, W. F. Seeking historical examples to illustrate key aspects of the nature of Science. Science \& Education, v. 17, n. 2-3, p. 249-263, 2008.

56 SILVA, C. C.; PRESTES, M. E. B. Aprendendo Ciência e sobre sua natureza: abordagens históricas e filosóficas. São Carlos: Tipographia Editora Expressa, 2013.

57 FORATO, T. C. M. A natureza da Ciência como saber escolar: um estudo de caso a partir da história da luz. Tese (Doutorado em Educação). Faculdade de Educação, Universidade de São Paulo, São Paulo, 2009.

58 FORATO, T. C. M.; MARTINS, R. A.; PIETROCOLA, M. History and nature of Science in high school: building up parameters to guide educational materials and strategies. Science \& Education, v. 21, n. 5, p. 657-682, 2012.

59 FORATO, T. C. M.; MARTINS, R. A.; PIETROCOLA, M. Historiografia e natureza da Ciência na sala de aula. Caderno Brasileiro de Ensino de Física, v. 28, n. 1, p. 27-59, 2011.

60 EL-HANI, C. N.; TAVARES, E. J. M.; ROCHA, P. L. B. Concepções epistemológicas de estudantes de Biologia e sua transformação por uma proposta explícita de ensino sobre História e Filosofia das Ciências. Investigações em Ensino de Ciências, v. 9, n. 3, p. 265-313, 2004.

61 MOREIRA, M. A.; MASSONI, N. T.; OSTERMANN, F. "História e epistemologia da Física" na licenciatura em Física: uma disciplina que busca mudar concepções dos alunos sobre a natureza da Ciência. Revista Brasileira de Ensino de Física, v. 29, n. 1, p. 127-134, 2007.

62 PEREIRA, G. J. S. A.; MARTINS, A. F. P. A inserção de disciplinas de conteúdo histórico-filosófico no currículo dos cursos de licenciatura em Física e em Química da UFRN: uma análise comparativa. Caderno Brasileiro de Ensino de Física, v. 28, n. 1, p. 229-258, 2011.

63 OKI, M. C. M.; MORADILLO, E. F. 0 ensino de história da química: contribuindo para a compreensão da natureza da Ciência. Ciência e Educação, v. 14, n. 1, p. 67-88, 2008.

64 PEDUZZI, L. O. 0.; TENFEN, D. N.; CORDEIRO, M. D. Aspectos da natureza da Ciência em animações potencialmente significativas sobre a história da Física. Caderno Brasileiro de Ensino de Física, v. 29, n. especial 2, p. 758-786, 2012.

65 MOURA, B. A. Formação crítico-transformadora de professores de Física: uma proposta a partir da história da Ciência. Tese (Doutorado em Ensino de Ciências) - Instituto de Física, Faculdade de Educação, Universidade de São Paulo, São Paulo, 2012.

66 Disponível em: <http://www.tekne.pro.br>. Acesso em: jul. 2013.

67 REIS, J. C.; GUERRA, A.; BRAGA, M.; FREITAS, J. History, Science and culture: Curricular experiences in Brazil. Science \& Education, v. 10, n. 4, p. 369-378, 2001.

68 BRAGA, M.; GUERRA, A.; REIS, J. C. The role of historical-philosophical controversies in teaching sciences: The debate between Biot and Ampère. Science geducation, v. 21, n. 6, p. 921-934, 2012.

69 GUERRA, A.; BRAGA, M.; REIS, J. C. History, Philosophy, and Science in a social perspective: A pedagogical project. Science \& Education, v. 22, n. 6, p. 1.485-1.503, 2013.

70 SILVA, C. C.; MOURA, B. A. A natureza da Ciência por meio do estudo de episódios históricos: 0 caso da popularização da óptica newtoniana. Revista Brasileira de Ensino de Física, v. 30, n. 1, p. 1.602, 2008

71 SILVA, C. C.; MOURA, B. A. Science and society: The case of acceptance of Newtonian optics in the eighteenth century. Science \& Education, v. 21, p. 1.317-1.335, 2012.

72 CORDEIRO, M. D.; PEDUZZI, L. 0. 0. Aspectos da natureza da Ciência e do trabalho científico no período inicial de desenvolvimento da radioatividade. Revista Brasileira de Ensino de Física, v. 33, n. 3, p. 3.601, 2011.

[Recebido em Agosto de 2013. Aceito para publicação em Março de 2014]

Revista Brasileira de História da Ciência, Rio de Janeiro, v. 7, n. 1, p. 32-46, jan | jun 2014 